\title{
Regulatory Bindings, Policy Uncertainty, and Market Access in Services"
}

\author{
Peter Egger, Joseph Francois, Bernard Hoekman, and Miriam \\ Manchin
}

\subsection{Introduction}

Unlike trade in goods, market access commitments for services exclusively comprise regulatory measures but never trade taxes. In other words, they are generally about non-tariff measures (NTMs). In some sectors foreign access may be limited or completely prohibited through quantitative restrictions, e.g. bans on foreign provision of broadcasting or transport services, or requirements that government officials fly on the national airline. More generally, services activities are often regulated. Differences in regulation may then result in additional costs for foreign providers when they contest a market. Because they involve sale of intangibles in the form of service flows rather than physical goods, there is

* This chapter is based closely on (and in some parts borrows from and/or updates) our earlier paper summarizing analysis of TiSA for a project assessing TiSA for the European Commission (Trade SIA in support of negotiations on a plurilateral Trade in Services Agreement - TiSA). Updated data are from Francois and Manchin (2016), which received support from the European Union's Seventh Framework Programme for research, technological development and demonstration under grant agreement no. 61350. While we acknowledge the support, all opinions are strictly those of the authors themselves. 
usually some form of direct interaction between service producers and customers. This means that establishment is more likely to be important for service exports than goods exports, resulting in an effective mix of cross-border and FDI related regulatory measures when we discuss market access in services.

While most trade agreements concluded since the mid-1990s reference trade in services and many include substantive provisions, ${ }^{2}$ analysts have found that frequently these do little to liberalize trade (Roy, 2011; Miroudot and Shepherd, 2014). Negotiations to expand the General Agreement on Trade in Services (GATS) as part of the WTO Doha Round (launched in 2001) failed. A subsequent initiative launched in 2012 by a group of WTO members to conclude a plurilateral Trade in Services Agreement (TiSA) is in limbo at the time of writing following the cessation of negotiations after the election of President Trump. The Comprehensive and Progressive Agreement on Trans-Pacific Partnership (CPTPP) includes services but does relatively little to go beyond the GATS commitments of participating countries (Gootiiz and Mattoo, 2017). Services have also been controversial in negotiations between high-income countries: in the context of the Transatlantic Trade and Investment Partnership

${ }^{1}$ See Francois and Hoekman (2010) for more extensive discussion on these points.

${ }^{2}$ Virtually all agreements to liberalize trade in services include goods trade as well. Dür, Baccini and Elsig (2014) find that only 1 per cent of extant agreements are pure services agreements and report that of a total of 587 agreements concluded since the late 1950s, 17 per cent include substantive provisions on services trade. Agreements covering services began to be negotiated in the early 1990s.

${ }^{3}$ See Ciuriak, Dadkhah and Xiao (2017) for an analysis of the CPTPP. 
(TTIP), civil society groups expressed strong concerns about opening public services sectors to greater foreign competition (Young, 2016).

Overall, trade agreements that include services are largely limited to commitments that 'lock in' prevailing policies as opposed to liberalization. Why this is the case is an important question given that services trade barriers are significant and services account for the majority of economic activity in more advanced countries - over 70 per cent of GDP and employment in the EU is created by services sectors. A significant share of value added embodied in goods reflects services, and the productivity of firms across a broad range of sectors depends on access to high-quality, competitively priced services (Lanz and Maurer, 2015). Various hypotheses have been put forward to explain the limited extent of services liberalization commitments observed in the GATS and trade agreements (Hoekman, 2008). A common feature of these hypotheses is the complex political economy of services liberalization that arises because trade often requires cross-border movement of service suppliers and the fact that many services are regulated.

In this chapter, we abstract from the reasons why liberalization is limited in trade agreements. Instead, we focus on another feature of trade agreements, one that is particularly prevalent in agreements covering services: they are instruments through which governments make commitments not to exceed a specified threshold level of trade restrictions. That is, we are interested in market access in services as it related to reducing the policy uncertainty that confronts traders. In particular, we focus on the market access impact of policy uncertainty arising from binding overhang, or the gap between bound 
commitments on policy and actual applied policy in international trade agreements as they relate to services. Binding overhang is a well-documented feature of the WTO system for both goods (Blackhurst, Enders and Francois, 1996; Francois and Martin, 2003) and for services (Hoekman, 1996; Borchert, Gootiiz and Mattoo, 2011). In the case of services, there is a substantial gap between commitments made both in the GATS and in preferential trade agreements and actual applied policy. This implies that governments retain substantial discretion to increase the restrictiveness of trade policies without violating the obligations they have undertaken in their trade agreements. ${ }^{4}$

Our analysis is limited to the effects of binding overhang for discriminatory policies, i.e. measures that target foreign services suppliers and restrict their market access. We abstract from the effects of domestic regulation and differences in domestic regulatory regimes. In practice regulatory heterogeneity will have trade effects that may be substantial, but to date trade agreements have done little to address this dimension of international services trade costs.

\subsection{Uncertainty and Market Access}

There are valid reasons to expect that policy uncertainty may itself suppress general macroeconomic conditions, including the incentives for international trade. One reason is that investors are in reality averse to risk. As such, increased

${ }^{4}$ Discussion on the salience of this feature of services trade agreements and options on how to close the gap between actual market access policies and bound commitments under the GATS began even before the Uruguay Round Agreements were signed (see Sauvé, 1995; Hoekman, 1996). 
risk, including from policy uncertainty, reduces the willingness of investors to commit resources. The end result is that, like a tax on investment returns, uncertainty about market conditions can drive reallocation of resources to other sectors. Indeed, while for this chapter we focus on the relatively narrow question of uncertainty linked to guaranteed conditions for market access in services, the linkages between macroeconomic conditions and trade barriers are deeper, and include both tariff and non-tariff measures. For example, Rodrik (1992, 1993), Francois (1996, 2001), Baldwin, Francois and Portes (1997), Gulen and Ion (2015), and Baker, Bloom and Davis (2016) all emphasize macroeconomic effects (e.g. the impact on incentives for investment) from policy uncertainty, while Francois and Martin $(1997,2004)$ and Handley (2014) focus specifically on the benefits of tariff bindings. In the context of policy commitments and investor protection, increased certainty of commitments can be seen as beneficial on several levels (again see Rodrik, 1992). Examples include both the Eastern Enlargement of the EU, and Mexico's simultaneous joining of the GATT and NAFTA as signalling a commitment to more stable policy regimes. 5 In the context of the WTO, developing countries were given negotiating credit in the Uruguay Round specifically for entering ceiling bindings on tariffs even when those were well above applied rates (Blackhurst, 1996), again signalling that WTO Members value bindings. The same concept of credit for bindings, even when applied policies do not actually have to change, was also contemplated for the Doha Round (Francois and Martin, 2003).

${ }^{5}$ See the discussion in Baldwin et al. (1997) and Francois (1997). 
In the context of services commitments in the GATS, gaps between bound and applied measures are the norm rather than the exception (Hoekman, 1996; Borchert et al., 2011, 2014). The 'GATS structure allows Members not to bind the status quo in many sectors. The fundamental question is whether GATS will induce Members to go further in future negotiating rounds' (Hoekman, 1996, p. 117). The challenge in negotiating trade agreements, including the recent Trade in Services Agreement (TiSA) negotiations, is in part to find a way to close this gap. Based on the assessment of Borchert et al. (2011), tabled commitments under the Doha agenda did not represent any real substantive change in this situation. While the question remained open in the case of the TiSA talks, the Comprehensive and Progressive Agreement for Trans-Pacific Partnership (CPTPP) does include some features that close the gap between bound commitments and actual policy (Ciuriak et al., 2017).

\subsection{Data and Methodology}

The approach we follow here is to estimate a reduced form trade cost following from the gap between bound policy commitments under the GATS and actual applied policy, using a gravity model.

\subsubsection{Data}

Our data come from a number of sources. Trade data come from an updated version of the Trade in Services Database available from the World Bank.

${ }^{6}$ http://data.worldbank.org/data-catalog/trade-in-services. 
Pairwise variables also come from a number of sources. Distance comes from the CEPII database, as do several other pairwise variables pertaining to colonial history, common border, etc. (Mayer and Zignago, 2006).

For services trade policy, we work with the World Bank Services Trade Restrictiveness Index (STRI) database. In the database, regulatory data are used to assign numerical scores indicating relative degrees of impact on openness. This may include for example ownership share restrictions when establishing an affiliate operation, or limits on the right to provide professional services based on nationality. Such scoring of regulatory measures is then classified based on the GATS modes of supply. The scores are then combined to yield STRIs by mode, and then also overall (Borchert et al., 2011, 2014).8 The STRI data provide valuable information linking regulation (inherently qualitative) to quantitative market access measures.

7 The GATS defines four modes through which services trade may occur: cross-border exchange of products; through movement of the consumer to the location of a foreign provider; through establishment (direct investment) by foreign suppliers in a market; and through the temporary cross-border movement of services suppliers.

${ }^{8}$ Further documentation and the underlying regulatory data are available online: http://data.worldbank.org/data-catalog/services-trade-restrictions.

${ }^{9}$ While the emphasis of the World Bank database is on market access (i.e. discriminatory measures), the OECD has a similar project supplying data that includes not only measures that are discriminatory, but also measures that impact on performance of domestic and foreign firms alike. In this sense, they blend market access and overall regulatory efficiency concepts. The OECD data and background documentation are also available online: www.oecd.org/tad/services-trade/services-trade-restrictiveness-index.htm These data are for fewer countries, however, while the World Bank also provides an easier route to the intra- and extra-EU STRI margins discussed below. 
We work here with an extension of the STRI data from Francois and Manchin (2016), who report both intra-EU and extra-EU index values for the EU Member States. In the case of EU Member States, the data from the World Bank report a blended index, reflecting a weighted average of intra-EU and extra-EU market access conditions. The extended data reflect a process of revisiting the original classification and scoring of regulatory measures as reported by the World Bank, and re-scored them for both intra-EU market access and extra-EU market access. This means that for the EU Member States, we have indicators of market access for other EU firms, as distinct from providers from third countries accessing the market of a Member State. This extension is needed because EU firms benefit from the Single Market in selling services within the EU. The Single Market is not complete, however, as EU Member States continue to maintain some restrictions on intra-EU trade in services. EU monitoring reveals there is still a substantial gap between the vision of a single EU-wide market for services and the reality reflected in restrictions that continue to be imposed by Member States on intra-EU trade reflecting public interest objectives (Monteagudo, Rutkowski and Lorenzani, 2012).

In addition to scoring the level of market access commitments in the GATS, the World Bank has also produced a separate breakdown of applied policies vs actual GATS commitments for the 103 countries in the database (Borchert et al., 2011). These data have been published for overall STRI levels at sector level, and not by mode. ${ }^{10}$ As part of the same project, the World Bank has also released recent estimates of trade costs, These trade costs are expressed as

10 The OECD has released a version of its own data from a similar exercise for the OECD countries (Miroudot and Pertel, 2015). 
tariff equivalents, for all 103 countries in the database (Jafari and Tarr, 2017). These represent estimates of trade costs for applied market access. In other words, they are estimates of the costs of restrictions on market access for services, as a percentage of the cost of delivery of those services. As Jafari and Tarr note, there are two approaches followed in the literature when estimating AVEs for services. The first is the gravity approach to AVE estimation, which has been employed for example by Francois (1999), Walsh (2006), Francois et al. (2007) and Kimura and Lee (2004). While this approach allows for estimation of overall levels of trade costs, it fails to link these to specific sets of policies and regulations. The second approach, pioneered by the Australian Productivity Commission, involves linking underlying regulatory measures to evidence on sectoral pricing and general market access. This second approach is the one followed for the World Bank estimates. Basically, the World Bank AVE estimates follow from the underlying regulatory data that form the basis for the World Bank indexes, which are processed using updates to the methodologies employed for the Productivity Commission-based estimates. The end results are AVEs that reflect the underlying structure of regulation. It should be stressed that because the data used to estimate the AVEs only provide information on discriminatory policy measures, the estimates of the AVEs themselves are also strictly for discriminatory barriers. They do not reflect costs faced by foreign firms because of regulatory inefficiency (i.e. regulatory costs that also affect domestic firms).

11 See Christen, Francois and Hoekman (2012) for further discussion on discriminatory vs non-discriminatory barriers to services trade and Crozet, Milet 
In essence, using a measure of the gap between bound market access and actual market access as a metric for sector-specific policy uncertainty linked to market access (i.e. how secure are current market access conditions) we estimate the iceberg trade cost necessary to yield the same identified impact on trade from this uncertainty. In effect, we use the binding overhang, or the policy space allowing for replacing current policy with a more protectionist one, as a metric for policy uncertainty.

\subsubsection{Estimating Equations}

We work with a gravity equation of cross-border services trade. The gravity model itself follows from a range of standard models (Deardorff, 1998; Head and Mayer, 2014). For bilateral trade in services, we have estimated a gravity equation using Poisson quasi-maximum likelihood (so allowing for zeroes in trade). ${ }^{12}$ This means we model bilateral trade in services as taking the following basic form:

(3.1) $E\left(v_{i, j, t} \mid X\right)=e^{\theta X_{i, j, t}}$

where

(3.2) $\theta^{\prime} X_{i, j, t}=\theta_{i, t}^{X}+\theta_{j, t}^{M}+\sum_{k} \theta_{k} z_{i, j, k, t}$.

and Mirza (2016) for an empirical analysis of the trade effects of nondiscriminatory regulation.

12 While with Poisson one does not discard zeroes from the data, we should note that Poisson assumes 'proportionality' about all numbers. Hence, an excess mass at zero is not accommodated. Only the heteroscedasticity of the residuals flowing from it is (where the heteroscedasticity is associated with parameter bias). 
In Equation (3.1) the term $v_{i, j, t}$ represents bilateral trade flows from exporter $i$ to importer $j$ in time period $t$, while in Equations (3.1) and (․․2), $\theta$ is the vector of coefficients applied to explanatory variables $X$, and the explanatory variables can themselves be broken down into time-varying exporter fixed effects $\theta_{i, t}^{X}$, time-varying importer fixed-effects $\theta_{j, t}^{M}$, and pairwise variables (some timevarying, some not) $z_{i, j, k, t}$. The time-varying importer and exporter fixed effects capture annual supply and demand related variables that are country specific. These variables are all discussed in more detail in what follows.

In estimating Equations (3.1) and (․․․), importer fixed effects will capture average or MFN levels of market access. At the same time, as we are able to distinguish between intra-EU and extra-EU market access, we have a measure of the margin of preference afforded to EU Member States to other EU Member States. This is measured as the difference from the average or MFN rate of protection captured by importer fixed effects. As this difference has the same coefficient as the MFN rate, and is the price elasticity (with AVEs) or STRI elasticity, it can be used when estimating the value of the price coefficient. This same approach is followed in CEPR (2009) and Egger et al. (2015) for estimation of tariff elasticities. We include two measures of trade restrictions for this purpose. Both are based on differences between external (MFN) and internal (intra-EU) market access measures.

Starting from Francois and Manchin (2016), the first measure is based on the extended STRI database. Since WTO commitments involve commitments on extra-EU market access, to examine the impact of overhang we focus on the difference between extra-EU actual market access, and the STRI values for GATS 
commitments, both measured in terms of STRI values. The second measure combines the STRI data with the Jafari and Tarr (2017) AVE estimates. Here we use the relative difference between intra- and extra-EU indexes to rescale the World Bank AVEs (based on the STRI data also as described above) to arrive at estimated intra-EU and extra-EU AVEs. For example, if the extra-EU STRI is twice the intra-EU STRI, this means the extra-EU AVE is then also scaled at twice the intra-EU AVE. In this second case, the coefficient applied to the AVE margin is theoretically identical to the price elasticity for services, just as it is when working with tariff data for goods. (Again, see for example Egger et al., 2015; ECORYS, 2009 for examples in the case of goods). While the regressions based on AVEs provide us directly with price elasticities, the STRI regressions serve as a robustness check. In both cases we treat intra-EU market access as bound at applied rates (based on EU policy related to the single market), and extra-EU market access as bound based on GATS bindings. In both cases, the average value of service restriction related trade costs is captured by the importer fixed effects for the full sample, while we obtain pairwise variation based on intra-EU and extra-EU levels of bindings (and AVEs) relative to actual market access, based on the World Bank data as discussed above. ${ }^{13}$ The average STRI values for intra- and extra-EU trade are reported in Table 3.1. In the table an index value of 0 means no restrictions, while an index of 100 means a market is fully closed.

${ }^{13}$ As a robustness check, we also included various pairwise dummies for other PTAs, but the EU is the only one for which we identify significant differences in market access linked to PTAs and customs unions for services. Therefore the specification reported here includes only the EU trade effects. 
Table 3.1

Blended and extra-EU STRI for market access in EU

\begin{tabular}{|c|c|c|}
\hline Sector & Original STRI & External STRI \\
\hline Overall & 17.97 & 25.25 \\
\hline Financial & 4.36 & 8.71 \\
\hline Banking & 1.82 & 3.75 \\
\hline Lending by banks & 1.82 & 3.63 \\
\hline Acceptance of deposits by banks & 1.82 & 3.63 \\
\hline Insurance & 8.38 & 16.50 \\
\hline Automobile Insurance & 8.63 & 16.75 \\
\hline Life Insurance & 10.50 & 21.25 \\
\hline Reinsurance & 6.00 & 11.50 \\
\hline Telecommunications & 1.88 & 2.50 \\
\hline Fixed-line telecommunications & 2.50 & 3.75 \\
\hline Mobile telecommunications & 1.25 & 1.25 \\
\hline Retail & 8.75 & 7.50 \\
\hline Transportation & 25.35 & 41.57 \\
\hline Air Passenger International & 27.63 & 43.50 \\
\hline Maritime Shipping International & 9.26 & 14.56 \\
\hline Maritime Auxiliary Services & 8.82 & 14.71 \\
\hline Road Freight Domestic & 35.00 & 70.00 \\
\hline Rail Freight Domestic & 36.25 & 38.75 \\
\hline Professional & 45.15 & 59.41 \\
\hline Accounting and Auditing & 43.25 & 55.00 \\
\hline Accounting & 33.25 & 44.75 \\
\hline Auditing & 53.25 & 65.25 \\
\hline Legal & 46.42 & 62.35 \\
\hline Legal Advice Foreign Law & 29.25 & 42.38 \\
\hline Legal Advice Domestic Law & 56.25 & 73.75 \\
\hline Legal Representation in Court & 53.75 & 70.94 \\
\hline
\end{tabular}

Source: Francois and Manchin (2016). Values are based on averages of EU Member State values from the extended STRI database.

\subsection{Results and Discussion}

Our regression results are reported in Table 3.2 for total services trade. The first specification is based on the AVEs for trade costs in services from Iafari and Tarr (2015) while the second instead uses the STRI indexes themselves as discussed above. Both specifications have the same basic overall fit, with the model 
explaining roughly 86 per cent of the sample variation in bilateral services trade in our 2005-11 panel (based on the pseudo R-squared statistic). Both the AVE and STRI coefficients are statistically significant. Our interpretation is that the AVE estimates provide the same overall fit as the underlying STRI data.

Table 3.2

Gravity regressions, total bilateral services trade

\begin{tabular}{|c|c|c|}
\hline & Specification 1 & Specification 2 \\
\hline \multirow[t]{2}{*}{$\ln$ (distance) } & -0.536 & -0.537 \\
\hline & $(45.09)^{* *}$ & $(45.46)^{* *}$ \\
\hline \multirow[t]{2}{*}{ Common colonial history } & -0.676 & -0.675 \\
\hline & $(4.38)^{* *}$ & $(4.38)^{* *}$ \\
\hline \multirow{2}{*}{ Shared ethnic language } & 0.467 & 0.456 \\
\hline & $(19.51)^{* *}$ & $(19.09)^{* *}$ \\
\hline \multirow[t]{2}{*}{ Shared border } & 0.194 & 0.207 \\
\hline & $(7.95)^{* *}$ & $(8.52)^{* *}$ \\
\hline \multirow[t]{2}{*}{ Former colonial relationship } & 0.305 & 0.306 \\
\hline & $(12.68)^{* *}$ & $(12.70)^{* *}$ \\
\hline \multirow[t]{2}{*}{$\ln (1+\mathrm{AVE})$} & -4.775 & \\
\hline & $(14.04)^{* *}$ & \\
\hline \multirow[t]{2}{*}{ Binding overhang (STRI based 0-100) } & -0.006 & -0.006 \\
\hline & $(3.33)^{* *}$ & $(3.28)^{* *}$ \\
\hline \multirow[t]{2}{*}{ Applied STRI (STRI based 0-100) } & & -0.026 \\
\hline & & $(13.97)^{* *}$ \\
\hline $\mathrm{N}$ & 34,457 & 34,457 \\
\hline pseudo R2 & 0.8619 & 0.8618 \\
\hline
\end{tabular}

Notes:

1. Bilateral services trade 2005-11.

2. Poisson quasi-maximum likelihood estimates.

3. AVE estimates are from \afari and Tarr (2015).

4. Policy variables are estimated based on intra-EU vs extra-EU values, as these vary with dyad and so are not subsumed by importer fixed effects.

5. Regressions include importer and exporter time-varying fixed effects. 
The AVE coefficient is -4.775 , and can be interpreted as the trade price elasticity. While it has different interpretations depending on the underlying model for the gravity equation (Armington, Eaton-Khortum, etc.), the estimated value of this coefficient is in line with trade elasticity estimates for goods.

We are particularly interested in the overhang coefficient in Table 3.2. By construction, this is a semi-elasticity, where each index point change in binding overhang based on the STRI values implies a -0.006 per cent change in the log value of trade. These can be interpreted as follows. Assume we have a fifteenpoint difference between the bound and applied STRI values. We would like to know how the estimated trade volume effect from this gap compares to the impact of applied trade restrictions, as a trade cost equivalent. Basically, defining the $\log$ of the estimated volume effect of overhang as $G_{j}$, this means we want to know the log AVE equivalent $\tilde{t}_{j}$ such that the log volume effect from the overhang (represented below as $G_{j}$ ) should equal the log volume effect from the $\log$ AVE equivalent $\tilde{t}_{j}$. This involves a two-step calculation. The overhang coefficient identifies the change in the log of trade (or the percentage change in trade) when the overhang itself changes (measured in units of the STRI). This is a measure in volume terms. We use this to identify the corresponding trade cost, given our price elasticity estimate from Table 3.2, consistent with this change in volume. To do this, note that the price coefficient (from the AVE term in Table $\underline{\text { 3.2) }}$ gives us the change in the log of trade when the AVE is increased by a certain amount. Taken together, these two coefficients let us determine the additional trade cost (as an AVE) needed to give us the same volume effect as we get from change in overhang.

$$
\text { (3.3) }-.006 G_{j}=-4.775 \tilde{t}_{j} \text {. }
$$


Rearranging Equation (3.3), we can obtain the AVE itself for our example.

$$
\tilde{t}_{j}=\ln \left(1+.01 A V E_{j}\right)=\frac{.006}{4.775} G_{j}
$$

From Equation (3.4), given the coefficient estimates in Table 3.2, the estimated AVE for a fifteen-point STRI overhang is 1.9 per cent. In other words, bringing the bindings in line with actual market access (binding at current market access) yields estimated trade volume effects in this case comparable to a 1.9 per cent reduction in trade costs, measured as a share of the cost of exports.

For a selection of countries, based on Equation (3.4) and coefficients in $\underline{\text { Tables } 3.1}$ and $\underline{3.2}$, Table 3.3 summarizes, for total trade in services, the estimated value of trade cost reductions linked to moving bindings to actual market access levels. These are to be interpreted as eliminating a trade cost expressed as a percentage of the cost of exporting services, and not as an estimate of total underlying trade costs. (Also recall these are averages for all services.) They represent potential cost savings, scaled as a percentage of the current value of services traded. Table 3.4 presents estimates for the same countries and for a more detailed set of sectors. In Table 3.4, we continue to use the overall service price elasticity estimate from Table 3.2. Note that the STRI data on bindings are more limited than the applied policy STRI data, in terms of sector coverage. As such we have fewer sectors in Table 3.4 than we do in Table $\underline{3.1}$. 
Table 3.3

Estimated trade cost savings (total services EBOPS 200) tariff equivalent from eliminating binding overhang, value expressed as a percentage of the cost of

\begin{tabular}{|c|c|c|c|}
\hline \multicolumn{4}{|c|}{ exporting services } \\
\hline & Bound STRI & Applied STRI & $\begin{array}{c}\text { AVE: estimated cost } \\
\text { savings (see text) }\end{array}$ \\
\hline Australia & 0.46 & 0.22 & 2.99 \\
\hline Canada & 0.53 & 0.26 & 3.51 \\
\hline Chile & 0.73 & 0.25 & 6.15 \\
\hline Chinese Taiwan & 0.62 & 0.33 & 3.70 \\
\hline Colombia & 0.81 & 0.27 & 7.04 \\
\hline Costa Rica & 0.95 & 0.49 & 5.93 \\
\hline European Union & 0.55 & 0.25 & 3.76 \\
\hline Japan & 0.57 & 0.33 & 3.05 \\
\hline Korea & 0.62 & 0.33 & 3.70 \\
\hline Mauritius & 0.76 & 0.23 & 6.84 \\
\hline Mexico & 0.70 & 0.40 & 3.89 \\
\hline New Zealand & 0.32 & 0.15 & 2.16 \\
\hline Norway & 0.55 & 0.27 & 3.68 \\
\hline Pakistan & 0.84 & 0.32 & 6.79 \\
\hline Panama & 0.65 & 0.40 & 3.24 \\
\hline Peru & 0.72 & 0.33 & 5.01 \\
\hline Turkey & 0.56 & 0.37 & 2.39 \\
\hline United States & 0.50 & 0.28 & 2.75 \\
\hline China & 0.51 & 0.48 & 0.32 \\
\hline Malaysia & 0.68 & 0.60 & 0.90 \\
\hline Philippines & 0.80 & 0.57 & 2.95 \\
\hline Thailand & 0.78 & 0.59 & 2.29 \\
\hline Vietnam & 0.42 & 0.32 & 1.24 \\
\hline
\end{tabular}

Source: Own estimates as described in text.

Table 3.4

Potential trade cost reduction equivalents by sector from bindings, as percentage points

\begin{tabular}{ccccccc}
\hline $\begin{array}{c}\text { Water } \\
\text { transpor } \\
t\end{array}$ & $\begin{array}{c}\text { Other } \\
\text { transpor } \\
\mathbf{t}\end{array}$ & $\begin{array}{c}\text { Commu } \\
\text { ni- } \\
\text { cations }\end{array}$ & $\begin{array}{c}\text { Trade, } \\
\text { distribu- } \\
\text { tion }\end{array}$ & Finance & $\begin{array}{c}\text { Insuranc } \\
\text { e }\end{array}$ & $\begin{array}{c}\text { Business } \\
\text { pro- } \\
\text { fessional } \\
\text { services }\end{array}$ \\
\hline
\end{tabular}




\begin{tabular}{|c|c|c|c|c|c|c|c|}
\hline Australia & 1.3 & 6.7 & 0.0 & 0.0 & 6.5 & 2.7 & 2.6 \\
\hline Canada & 6.5 & 3.2 & 0.0 & 0.0 & 6.5 & 3.2 & 3.1 \\
\hline Chile & 11.3 & 9.9 & 3.2 & 9.9 & 8.2 & 1.6 & 6.3 \\
\hline $\begin{array}{r}\text { Chinese } \\
\text { Taipei }\end{array}$ & 5.2 & 4.8 & 0.0 & 6.5 & 6.5 & 2.1 & 3.4 \\
\hline Colombia & 12.7 & 13.4 & 0.0 & 13.4 & 8.2 & 2.1 & 7.9 \\
\hline Costa Rica & 9.9 & 6.5 & 8.2 & 13.4 & 3.2 & 7.0 & 4.1 \\
\hline $\mathrm{EU}$ & 9.0 & 5.0 & 0.3 & 1.1 & 6.0 & 3.0 & 1.1 \\
\hline Japan & 8.5 & 4.8 & 0.0 & 0.0 & 6.5 & 3.2 & 0.7 \\
\hline Korea & 5.2 & 4.8 & 0.0 & 6.5 & 6.5 & 2.1 & 3.4 \\
\hline Mauritius & 11.3 & 6.7 & 0.0 & 13.4 & 8.2 & 1.1 & 8.6 \\
\hline Mexico & 6.5 & 0.0 & 0.0 & 0.0 & 4.8 & 3.2 & 5.0 \\
\hline $\begin{array}{l}\text { New } \\
\text { Zealand }\end{array}$ & 3.8 & 0.0 & 0.0 & 0.0 & 6.5 & 2.7 & 0.9 \\
\hline Norway & 8.6 & 6.6 & 0.0 & 1.6 & 5.5 & 2.5 & 1.1 \\
\hline Pakistan & 9.2 & 13.4 & 0.0 & 13.4 & 4.8 & 2.7 & 8.9 \\
\hline Panama & 10.6 & 4.9 & 9.9 & 0.0 & 0.0 & 0.5 & 2.9 \\
\hline Peru & 10.6 & 13.4 & 0.0 & 6.5 & 0.0 & 0.0 & 7.6 \\
\hline Turkey & 6.5 & 0.0 & 0.0 & 13.4 & 2.4 & 4.3 & 0.0 \\
\hline $\begin{array}{l}\text { United } \\
\text { States }\end{array}$ & 10.6 & 6.7 & 0.0 & 0.0 & 6.5 & 1.1 & 0.3 \\
\hline China & 0.6 & 0.0 & 0.0 & 0.0 & 1.6 & 0.0 & 1.1 \\
\hline Malaysia & 0.6 & 3.2 & 3.2 & 9.9 & 3.2 & 2.7 & 0.0 \\
\hline Philippines & 0.0 & 0.0 & 3.2 & 6.5 & 3.2 & 1.1 & 4.7 \\
\hline Thailand & 3.2 & 4.8 & 3.2 & 9.9 & 1.6 & 1.6 & 1.3 \\
\hline Vietnam & 0.6 & 1.6 & 0.0 & 0.0 & 2.4 & 1.6 & 1.6 \\
\hline
\end{tabular}

Source: Own calculations as discussed in text.

The pattern of estimates in Tables 3.3 and $\underline{3.4}$ reflects a number of factors. One is that, because of the process of Chinese accession to the WTO, existing WTO Members were quite aggressive with China. As a result, bindings are generally at the actual applied policy, in terms of MFN-based market access conditions. This means there is no real gain to be had in the case of removing 
binding overhang in China. ${ }^{14}$ A similar case, though not quite as extreme, applies to Vietnam. On the other hand, for many of the other CPTPP countries included in the table there should be gains from simply binding market access at current levels (e.g. Australia, New Zealand, Japan ...).

\section{Concluding Remarks}

A stylized fact that emerges from the literature assessing and analysing trade agreements spanning services is that these generally do relatively little to liberalize trade. Instead, their main purpose seems to be to provide a mechanism through which states agree to reduce policy uncertainty by making commitments not to exceed a threshold level of trade restrictiveness. These policy bindings usually leave a substantial degree of discretion to raise barriers - there is significant water in the bindings - but nonetheless have value from a market access perspective by defining an upper bound on the level of protection that a firm may confront. The estimates discussed above suggest that a renewed push for more effective market access policy bindings in the WTO context may yield not only a basis for future negotiated gains, but also immediate gains in market access. Like goods, security of market access through effective services policy bindings matters.

${ }^{14}$ Analysis of the effects of the very limited water in China's WTO tariff bindings for goods has shown that this acted as an effective constraint on trade policy choices during the 2008-9 global financial crisis. See Gawande, Hoekman and Cui (2015). 